\title{
Cytomorphological Characteristics of a Colchicine Induced Chimeric Mutant in Mulberry
}

\author{
K. Vijayan, S. P. Chakraborti, B. N. Roy, M. Setua and S. M. H. Qadri \\ Central Sericultural Research and Training Institute, Berhampore, West Bengal, India-742 101 \\ Accepted September 17, 1997
}

\begin{abstract}
Summary Cytomorphological and phytochemical studies in a chimeric mutant obtained through colchicine treatment in mulberry were conducted. Uniform distribution of ploidal chimera $(2 n+4 n)$ was detected in different vegetative parts. Meiosis in the chimeric plant was highly irregular. Persistence of chimera in vegetative clonal generations was observed. Distinct morphological changes along with an increase in phenol and a decrease in sugar content were observed in the mutant. Significance of ploidal chimera in the improvement of mulberry is discussed.
\end{abstract}

There are many reports dealing with induction of tetraploids in mulberry (Morus spp.) (Das et al. 1970, Dwivedi et al. 1986). Occurrence of chimeric mutants through colchicine treatment was reported by Seki and Oshikane (1957) and Tojyo (1966). However, no information is available on the chromosomal behaviour in chimeric tissue during both mitotic and meiotic cell divisions. Similarly, knowledge on the phytochemical changes caused by chimera and the stability of chimera in clonal generations was found very much essential to exploit them for the improvement of this foliage crop.

In this study a comparative account of cytological, morphological, anatomical and phytochemical aspects of a chimeric mutant is presented.

\section{Materials and methods}

One phenotypically distinct mutant isolated from 15 colchicine treated clones of a diploid male variety $\mathrm{C} 776$ was used for the study. The chimeric plant was multiplied vegetatively to study the stability of chimeric characters in clonal generations. Morphological, anatomical and phytochemical studies were carried out on two year old plants. Stomatal frequency, size, and number of chloroplast in guard cells were examined after decolourising the leaves in 1:3 aceto-alcohol and subsequent staining with $2 \%$ Iodine solution $\left(\mathrm{KI}_{3}\right)$ for $1 \mathrm{~min}$.

Total soluble sugar, protein and phenols were estimated from fresh leaves following Morris (1948), Lawry et al. (1951) and Bray and Thrope (1954) respectively.

Somatic chromosomes were studied from shoot and leaf tips pre-treated in para-dichlorobenzene (PDB) for $4 \mathrm{hr}$ at $12^{\circ} \mathrm{C}$ followed by fixation in propionic-ethanol $(1: 3)$ overnight. Fixed samples after hydrolysis in $1 \mathrm{~N} \mathrm{HCl}$ were stained in $2 \%$ propionic-orcein. Meiotic chromosomes were studied from unopened flower buds of male catkins fixed in propionic-ethanol (1:3) for $72 \mathrm{hr}$ and stained with propionic-carmine (2\%).

\section{Results}

The mutant while exhibiting an increase in plant height, size and fresh weight of leaves and number of chloroplasts in the guard cells showed a decrease in internodal distance (Table 1). Likewise, the leaves were thick and dark green with smooth texture (Fig. 1). Marked increase in leaf 
Table 1. Morphoanatomical and phytochemical components of leaf in control plant and chimeric mutant of Morus cv. C776

\begin{tabular}{lcc}
\hline \multicolumn{1}{c}{ Characters } & Control plant & Chimeric mutant \\
\hline Morphoanatomical: & & \\
Plant height $(\mathrm{cm})$ & $38.0 \pm 1.52$ & $41.0 \pm 5.19$ \\
Leaf length $(\mathrm{cm})$ & $18.4 \pm 1.48$ & $19.9 \pm 6.03$ \\
Leaf width $(\mathrm{cm})$ & $11.1 \pm 0.96$ & $14.9 \pm 1.24$ \\
Leaf thickness $(\mu \mathrm{m})$ & $134.4 \pm 6.86$ & $168.7 \pm 6.60$ \\
Leaf weight $(\mathrm{g})$ & $2.4 \pm 0.41$ & $3.8 \pm 0.70$ \\
Internodal distance $(\mathrm{cm})$ & $4.1 \pm 0.69$ & $2.6 \pm 0.31$ \\
Stomatal length $(\mu \mathrm{m})$ & $14.0 \pm 3.20$ & $19.3 \pm 3.20$ \\
Stomatal width $(\mu \mathrm{m})$ & $12.7 \pm 1.60$ & $16.7 \pm 1.40$ \\
Stomatal frequency $\left(\right.$ per $\left.\mathrm{mm}^{2}\right)$ & $1072.2 \pm 108.3$ & $800.0 \pm 108.0$ \\
Guard cell chloroplasts $(\mathrm{no})$. & $9.9 \pm 1.7$ & $19.0 \pm 4.7$ \\
Phytochemical: $(\mathrm{mg} / \mathrm{g}$ fresh wt.) & & $14.8 \pm 0.22$ \\
Phenol & $9.1 \pm 1.17$ & $25.6 \pm 1.56$ \\
Protein & $18.4 \pm 1.10$ & $18.6 \pm 1.24$ \\
Sugar & $24.3 \pm 4.40$ & \\
\hline
\end{tabular}

width $(14.9 \pm 1.24 \mathrm{~cm})$, leaf thickness $(168.7 \pm 6.6 \mu \mathrm{m})$ and stomatal size $(19.3 \pm 3.2 \times 16.7 \pm 1.4 \mu \mathrm{m})$ was observed, along with a reduction in the stomatal frequency $(800 \pm 108)$. Distinct variation was observed in sugar, protein and phenol contents in the leaves of mutant and diploid plants. In the mutant phenol $(14.8 \pm 0.22 \mathrm{mg})$ and protein $(25.6 \pm 1.56 \mathrm{mg})$ were high whereas soluble sugar $(18.6 \pm$ $1.24 \mathrm{mg}$ ) was low (Table 1).

Though both plants expressed same sex, a remarkable reduction in the frequency of flowers coupled with delay in flowering up to 20-25 days was observed in the mutant.

The somatic cells of the normal plant contained 28 chromosomes consisting of 1 pair of long chromosomes and 13 pairs of small graded chromosomes (Fig. 2) where as in the mutant cells with 28 chromosomes (Fig. 4) and 56 chromosomes (Fig. 5) were seen in the form of ploidal chimera. The frequency of tetraploid cells in the original mutant was $43.41 \pm 3.64 \%$ and that in the clones was $45.06 \pm 7.12 \%$. The distribution of $2 \mathrm{n}$ and $4 \mathrm{n}$ cells in the meristem was uniform from peripheral to central region exhibiting a heterogeneous mixture of $2 n$ and $4 n$ cells.

In the control plant meiosis was regular with normal distribution of 14 bivalents in metaphase I. In mutant plants it was highly irregular. High percentage of bivalent $(50.0 \%)$ along with 5 different types of chromosomal configurations, monovalents to quadrivalents, were recorded. Frequency of monovalents and trivalents was very low as compared to that of bivalents and quadrivalents (Table 2). The quadrivalents were seen in the form of a cross or a ring of 4 chromosomes (Figs. 7 , 8).

Regular separation of chromosomes was noticed in diploid cells in telophase I (Fig. 9). High irregularity comprising of a lag of whole bivalent and late separation was observed in the tetraploid cells in telophase I (Fig. 10). Moreover, a lag of 1 chromosome (Fig. 11), 3-4 chromosomes (Figs. $12,13)$ and formation of micronuclei due to the loss of laggard were also detected in the chimeric mutant (Fig. 14). Meiotic chromosomes in clonal generations also exhibited similar kind of behaviour.

\section{Discussion}

Occurrence of periclinal chimera due to colchicine treatment was reported in some varieties of mulberry (Tojyo 1966). Most of the colchicine induced periclinal or sectorial chimeric plants showed variation in thickness and colour of leaves due to partitioning of diploid and tetraploid cells into different patches (Sikdar and Jolly 1994). No such patches was observed in the present mutant. 

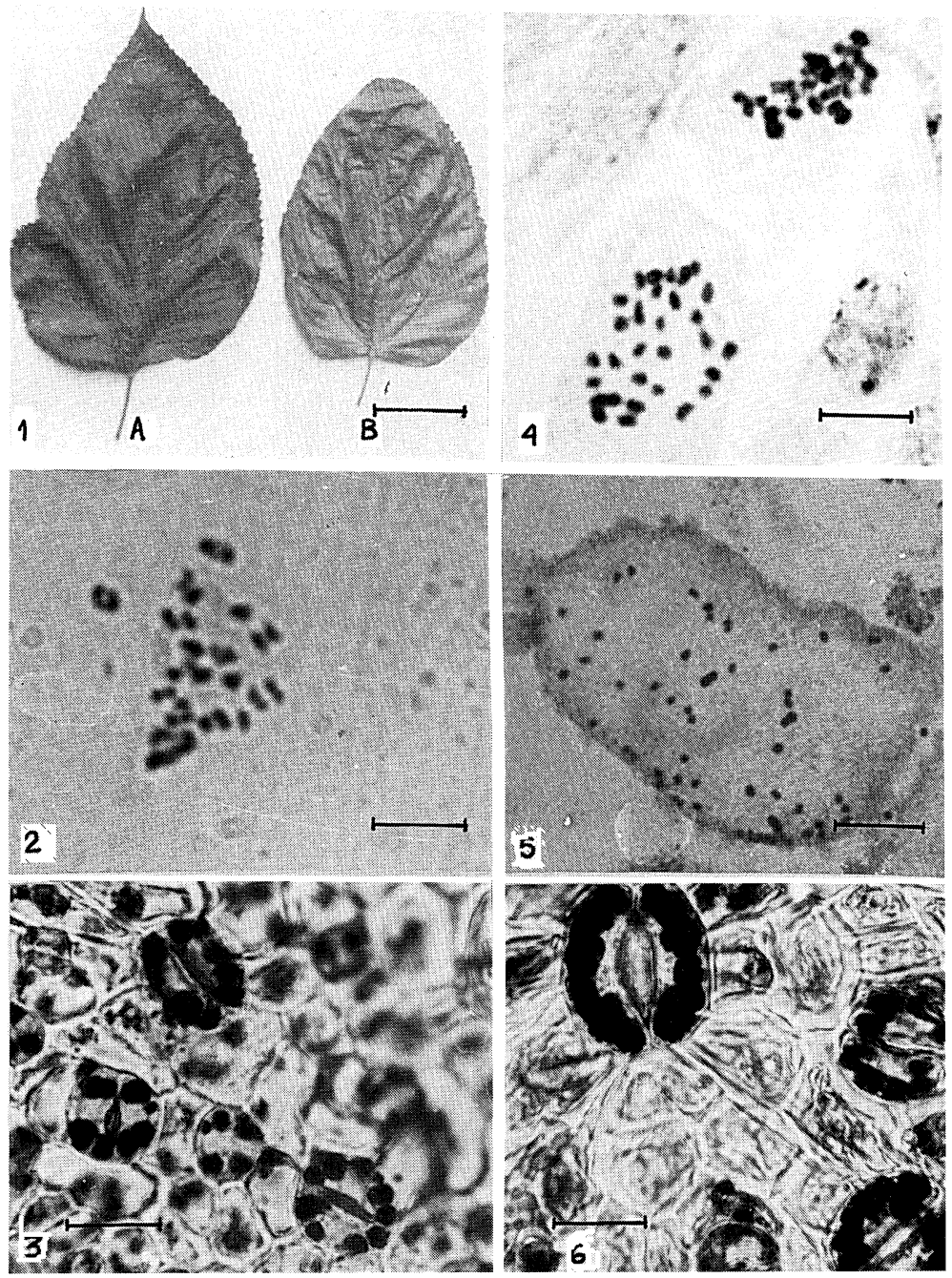

Figs. 1-6. Leaf, stomata and somatic chromosomes of diploid and mixoploid mulberry. 1) Leaves of mixoploid (A) and diploid (B) mulberry $(B a r=6 \mathrm{~cm})$. 2) Somatic chromosomes of diploid $(2 \mathrm{n}=28)$ normal plants $(\mathrm{Bar}=6 \mu \mathrm{m}) .3)$ Stomata with darkly stained chloroplast of diploid plant $(\mathrm{Bar}=11 \mu \mathrm{m}) .4)$ Diploid $(2 \mathrm{n}=28)$ somatic chromosome from mixoploid plant $(\mathrm{Bar}=6 \mu \mathrm{m})$. 5) Tetraploid somatic chromosomes $(2 \mathrm{n}=4 \mathrm{x}=56)$ from mixoploid plant $(\mathrm{Bar}=2 \mu \mathrm{m})$. 6) Stomata of mixoploid plant $(\mathrm{Bar}=10 \mu \mathrm{m})$.

Table 2. Chromosome configuration at metaphase I in chimeric mutant

Chromosomal configuration

Percentage of cells
50.0

8.0

6.0

6.0

4.0

12.0

14.0

On the other hand the increase in thickness and greenness of the lamina was uniform, thereby, the existence of sectorial chimera is ruled out in this mutant. Possible explanation for such uniform distribution of diploid and tetraploid cells is that at the time of colchicine treatment those cells which were at metaphase stages may have undergone polyploidisation while others remained unaffected at premitotic stage. After resumption of growth both diploid and tetraploid cells were intermixed resulting a mixoploid composition. This mixoploidy was further confirmed by the inter- 

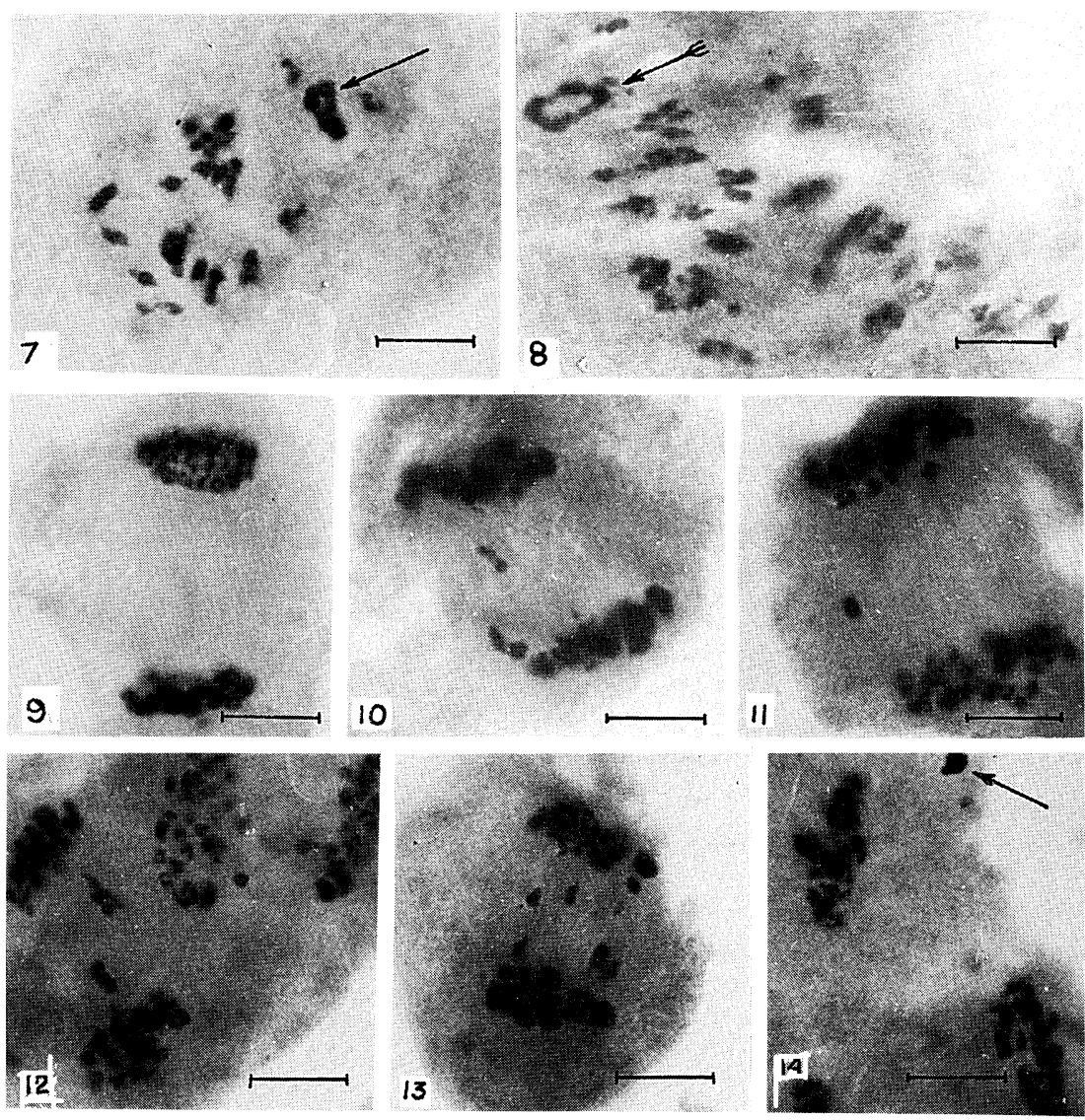

Figs. 7-14. Meiosis in mixoploid mulberry $(\operatorname{Bar}=5 \mu \mathrm{m})$. 7,8) Metaphase plate showing formation of multivalents, arrow indicate quadrivalent in the form of cross ( $>$ ) and ring ( 7 ) of 4 chromosomes. 9) Telophase I showing normal chromosomal separation. 10) Lag of bivalents in telophase. 11) Lag of 1 chromosome in late anaphase. 12,13) Lag of multivalents and 3-4 chromosomes in telophase. 14) Micronuclei $(\neg)$ resulting from "lost" laggards.

mixed distribution of diploid and tetraploid cells in PMCs. Similar distribution of $2 \mathrm{n}$ and $4 \mathrm{n}$ cells was also recorded in the vegetative clones of the chimeric mutant. This finding clearly reveals the stability of the ploidal chimera in vegetative clones of this mutant. However, the high irregularity in the meiosis does not favour the genotype to transmit chimeral characters through sexual generations. However, tropical mulberries being effectively propagated through stem cuttings, the beneficial transformation obtained in the mutant could be used for commercial utilization.

Another important observation recorded in this mutant was the increase of leaf phenol and protein together with a decrease in the sugar content. This change in phenol and sugar content is reported to enhance tolerance to fungal disease in crop plants (Chatopadhyay 1989). Such kind of changes in qualitative characters due to colchicine effect was also recorded in sorghum (Erichsen et al. 1962). Above biochemical changes therefore can also be used for investigation on disease resistance in mulberry.

\section{References}

Bray, H. and Thrope, W. V. 1954. Analysis of phenolic components of interest in metabolism. Methos. Biochem. Anals. 1: 27-52. 
Chattopadhyay, A. K. 1989. Relationship of phenols and sugars in Alternaria blight resistance of rape seed mustard. Indian J. Mycol. Res. 27: 195-199.

Das, B. C., Prasad, D. N. and Sikdar, A. K. 1970. Colchicine induced tetraploids of mulberry. Caryologia 23: $283-293$.

Dwivedi, N. K., Sikdar, A. K., Dandin, S. B. and Joolly, M. S. 1986. Colchicine induced tetraploidy in mulberry I: Morphological, anatomical and cytological investigations in cultivar RFS-135. Cytologia 51: 393-401.

Erichsen, A. W., Franzke, C. J., Sanders, M. E. and Ross, J. G. 1962. Colchicine induced mutation affecting qualitative characters in sorghum. J. Hered. 53: 304-308.

Lawry, O. H., Rosebrough, N. J., Farr, A. L. and Randall, R. J. 1951. Protein measurements with folin-phenol reagent. J. Bio. Chem. 193: 265-275.

Morris, D. L. 1948. Quantitative determination of carbohydrates with dreywood anthrane reagent. Science 107: $254-255$.

Seki, H. and Oshikane, K. 1957. Studies on polyploid mulberry tree (II). On the morphology of mixoploid mulberry trees induced by colchicine treatment. Res. Rep. Fac. Text. Seric. Shinshu Univ. Japan. 7: 5-11.

Sikdar, A. K. and Jolly, M. S. 1994. Induced polyploidy in mulberry (Morus spp.): induction of tetraploids. Sericologia 34: 105-116.

Tojyo, I. 1966. Studies on polyploid mulberry tree (1). Breeding of artificial autotetraploids. Bull. Sericult. Exp. Sta. Japan. 20: $187-207$. 